\title{
Expanding the evidence base on comprehensive care for survivors of sexual violence in sub-Saharan Africa
}

Population Council

Follow this and additional works at: https://knowledgecommons.popcouncil.org/departments_sbsr-rh

Part of the Demography, Population, and Ecology Commons, Domestic and Intimate Partner Violence Commons, Family, Life Course, and Society Commons, Gender and Sexuality Commons, and the International Public Health Commons

How does access to this work benefit you? Let us know!

\section{Recommended Citation}

"Expanding the evidence base on comprehensive care for survivors of sexual violence in sub-Saharan Africa," Completion report for the period November 2009-December 2013. Nairobi: Population Council, 2014. 


\title{
EXPANDING THE EVIDENCE BASE ON COMPREHENSIVE CARE FOR SURVIVORS OF SEXUAL VIOLENCE IN SUB-SAHARAN AFRICA
}

\author{
Completion Report
}

For the Period November 2009 - December 2013

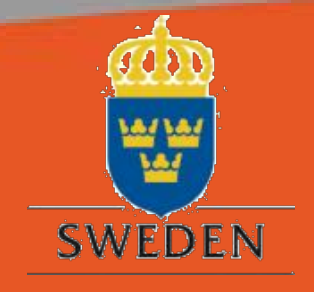

Norad

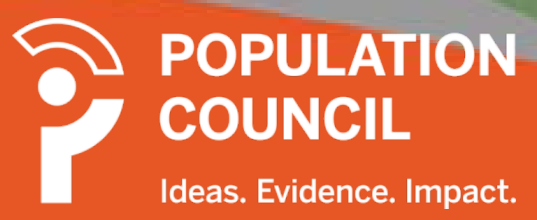




\title{
Expanding the Evidence Base on Comprehensive Care for Survivors of Sexual Violence in sub-Saharan Africa
}

\author{
Completion Report
}

For the Period

November 2009 - December 2013

Submitted to:

The Swedish-Norwegian Regional HIV and AIDS Team for Africa, Embassy of Sweden, Lusaka

Submitted by:

The Population Council, Nairobi

May 2014

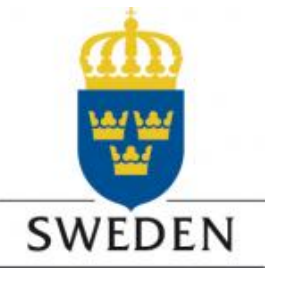




\section{Table of Contents}

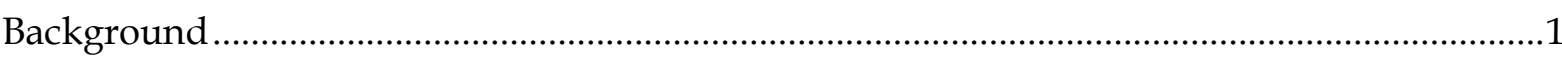

Result 1: Best Practices in SGBV service provision tested and rigorously documented............1

Result 2: South-South TA through a network of implementing partners...................................

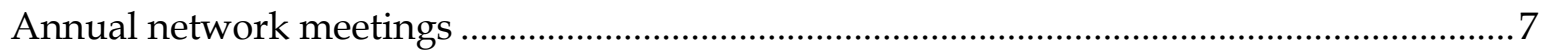

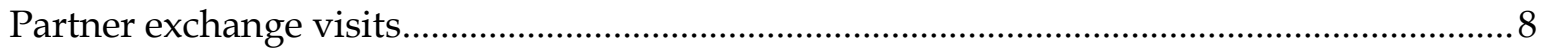

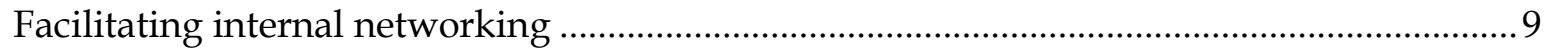

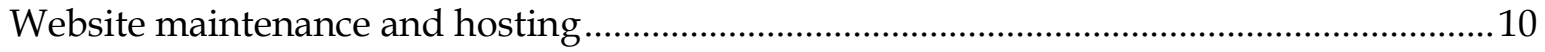

Result 3: Policy and programs influenced through the dissemination of best practices

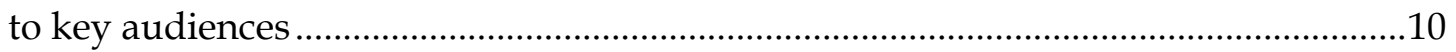

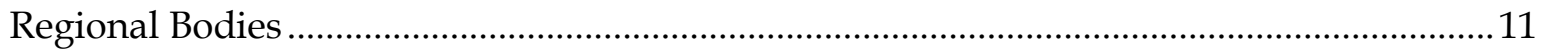

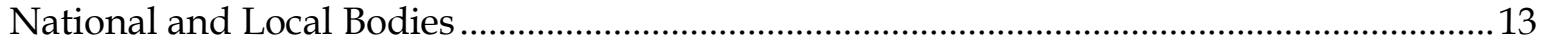

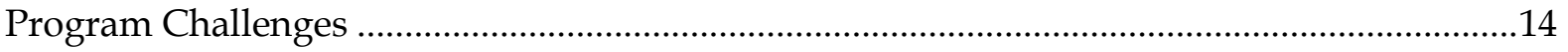

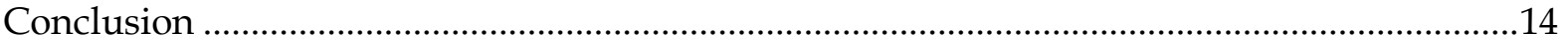

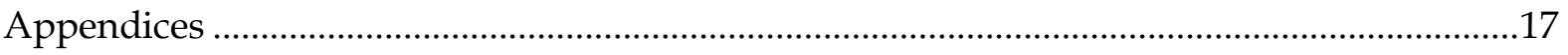

Appendix 1: Reports and Papers Published and Presented under the Expanding the Evidence Base on Comprehensive Care for Survivors of Sexual Violence in Sub-Saharan Africa Program

Appendix 2: Evidence of National and Local Impact Under the Expanding the Evidence Base on Comprehensive Care for Survivors of Sexual Violence in Sub-Saharan Africa Program. 25 


\section{Background}

The Expanding the Evidence Base on Comprehensive Care for Survivors of Sexual Violence in SubSaharan Africa program was a four-year agreement between the Swedish-Norwegian Regional HIV and AIDS Team for Africa, Embassy of Sweden, Lusaka ('the S-N Team'), and the Population Council. From 2009 to 2013, the program sought to mitigate the impact and incidence of sexual and gender-based violence (SGBV) in Sub-Saharan Africa by strengthening the capacities of medical, legal, and justice sectors to care for survivors of such violence. This approach was intended to serve the S-N Team's larger development objectives of preventing HIV transmission in Sub-Saharan Africa and promoting the sexual, reproductive and human rights of survivors across the region.

Over this four-year period, the program aimed to achieve the following results:

1. Best practices in SGBV service provision tested and rigorously documented;

2. South-South technical assistance (TA) provided through a network of implementing partners; and

3. Policy and programs influenced through the dissemination of best practices to key audiences.

This report provides an overview of the results achieved under this program, the impact observed in regard to national and regional SGBV issues by the completion of the program, and the challenges experienced during the program period.

\section{Result 1: Best Practices in SGBV service provision tested and rigorously documented}

A network of implementing partners across the East and Southern Africa region (known as the 'Africa Regional SGBV Network') served as the core of the program from 2009 to 2013. A total of six partners were supported by the program to implement individual projects during this period, as outlined in Table 1.

Table 1: Implementing Partners, 2009-2013

\begin{tabular}{|l|l|l|}
\multicolumn{2}{|c}{ Country } & \multicolumn{2}{c|}{ Project Title } \\
\multirow{2}{*}{ Kenya } & $\begin{array}{l}\text { Improving the collection, documentation, and utilization of medico- } \\
\text { legal evidence in Kenya }\end{array}$ & $\begin{array}{l}\text { Liverpool VCT, Care and Treatment } \\
\text { (LVCT), Kenya Ministry of Health }\end{array}$ \\
\cline { 2 - 3 } & $\begin{array}{l}\text { Assessing acceptability and feasibility of screening for IPV in public } \\
\text { health care settings in Kenya }\end{array}$ & $\begin{array}{l}\text { Kenyatta National Hospital, Population } \\
\text { Council }\end{array}$ \\
\hline \multirow{2}{*}{ Malawi } & Testing feasibility of police provision of emergency contraception & $\begin{array}{l}\text { Malawi Police Service, Ministry of Health, } \\
\text { Malawi Human Rights Resource Centre }\end{array}$ \\
\hline $\begin{array}{l}\text { South } \\
\text { Africa }\end{array}$ & $\begin{array}{l}\text { Testing feasibility, impact, and cost-effectiveness of the Zero- } \\
\text { Tolerance Village Alliance Model }\end{array}$ & $\begin{array}{l}\text { Thohoyandou Victim Empowerment } \\
\text { Programme (TVEP) }\end{array}$ \\
\hline Swaziland & $\begin{array}{l}\text { Testing feasibility and effectiveness of a comprehensive SGBV } \\
\text { prevention project for in-school girls in Swaziland; } \\
\text { Developing national guidelines for a multisecotral response }\end{array}$ & $\begin{array}{l}\text { Swaziland Action Group Against Abuse } \\
\text { (SWAGAA) }\end{array}$ \\
\hline Zambia & $\begin{array}{l}\text { Scaling up the Copperbelt Model of Integrated Care (CMIC); } \\
\text { Assessing feasibility of improving PEP access for sexual violence } \\
\text { Survivors through Zambian Police Services }\end{array}$ & $\begin{array}{l}\text { Zambia Ministry of Health, Zambia Police } \\
\text { Service, Population Council }\end{array}$ \\
\hline
\end{tabular}


Through this structure, six best practices in SGBV service provision were tested in 5 countries in East and Southern Africa, with their processes and findings rigorously documented. A commonality shared by these best practices is their innovation, coupled with their applicability for low-resource settings which characterize the contexts in which many survivors in sub-Saharan Africa live. Furthermore, each best practice embraces the ethos of the Africa Regional SGBV Network ('the Network'), which recognizes that survivors require access to multi-sectoral services, while also acknowledging that it may not be feasible, appropriate, or cost-effective to deliver all services in one location. The best practices are highlighted below, and detailed reports documenting each of these practices may be accessed here: http://www.svri.org/popcouncil.htm.

\section{Best Practice \#1: Using a locally-assembled 'rape kit' coupled with a multisectoral provider training model to improve the collection, documentation, and utilization of medico-legal evidence}

In partnership with the Kenya Ministry of Health $(\mathrm{MoH})$, Liverpool VCT, Care and Treatment (LVCT) implemented to a study focused on improving systems for collecting, documenting, and utilizing medico-legal evidence in Kenya. Prior to this study, rape kits for facilitating forensic evidence collection were non-existent in public health facilities in Kenya, resulting in inefficient service provision for survivors of rape during the traumatic post-rape period. The introduction of this rape kit, designed specifically for low-resource settings, served to streamline evidence collection and improve evidence-handling in public health facilities. Providers from the medical (doctors, nurses, clinical officers, laboratory technicians) and justice sectors (police officers stationed at Gender Desks, and prosecutors who had ever handled rape cases) were jointly trained on forensic examination, utilization of the rape kit, evidence documentation using national post-rape care and police medical record forms, and on their responsibility to enlighten survivors about the importance of having completed forms returned to a police station. This joint training of providers enhanced communication between the sectors and thus enhanced referral linkages as well.

Findings from the evaluation of this intervention indicated a significant difference between the intervention and comparison sites in provider completion of post-rape care forms (Chi square $16.45, \mathrm{p}=0.000 ; 95 \% \mathrm{CI})$. At endline, intervention site providers were over thrice as likely as their comparison site peers to have filled out the police form for survivors. The completion of both forms is required for increasing the likelihood of medico-legal evidence being used in court. By the endline period, providers also perceived that using the rape kit helped to reduce survivor trauma by ensuring that the collection of different kinds of forensic evidence occurred in one location and with one provider.

Challenges identified during this study, however, included the lack of storage facilities within police stations for evidence collected by both police and health care workers (particularly, for survivors' clothing). This infrastructural issue remains a barrier to systematic collection of forensic evidence. 


\section{Best Practice \#2: Routine screening for the detection of and response to intimate partner violence (IPV)}

In collaboration with Kenyatta National Hospital (KNH), the Population Council's Kenya implemented and tested a 'routine screening' intervention in limited-resource, public health care contexts, given that evidence is lacking on the utility of routine IPV screening in healthcare settings in developing countries.

Proponents of routine screening argue it is now a standard of care in many industrialized countries, with research indicating its effectiveness in identifying chronic cases of domestic violence or IPV. Others, however, argue that routine screening may have a negative impact on women in environments where providers cannot respond appropriately, where privacy and confidentiality are not guaranteed, where referral services and linkages are lacking, and where clients and providers alike may be unwilling to have the issue addressed. Many of these potential barriers are presumed, however, and had not been fully tested in health care settings in developing countries at the time of this study. The intervention involved training providers at $\mathrm{KNH}$ to appropriately screen women routinely for IPV, and to refer IPVpositive clients to the on-site GBV clinic for further care.

Study results indicated that $8 \%$ of all clients screened $(n=1210)$ reported experiencing some form of IPV. Psychological violence was the most commonly-reported form of IPV overall, followed by sexual violence, and, lastly, physical violence. Two-thirds of IPV-positive clients identified by providers through screening were youth as defined by the Kenya National Youth Policy, 2006 (18-30 years). Providers demonstrated capacity to screen for IPV and provide referrals for further services. Providers referred nearly $80 \%$ of those reporting a current experience of IPV to the GBV clinic. Women screened at the HIV comprehensive care center were the most likely to be positively screened for IPV (24\%), followed by women screened at the Youth Center $(17 \%)$, and those screened at the antenatal care center $(3 \%)$. Resources to protect confidentiality were perceived as adequate by clients, and client satisfaction with IPV services was high.

Referral uptake was relatively low, however, compared to the high level of provider referral. Overall, $40 \%$ of those reporting IPV presented at the GBVRC for further care after referral. Data analysis showed that establishing the minimum level of staffing required at GBV clinics during opening hours, and reminders for providers to refer IPV-positive clients after identifying them could help to remedy this situation.

\section{Best Practice \#3: Decentralizing emergency medical responses for rape survivors to police (police provision of emergency contraception)}

Previous research under the Network demonstrated that police stations are often the first and only point of contact for survivors of rape in the region. In response to this reality, a model involving the provision of emergency contraception (EC) by police to survivors of SGBV, followed by referral to a health facility for comprehensive care was developed. The Malawi Police Service, Ministry of Health $(\mathrm{MoH})$, and Malawi Human Rights Resource 
Centre (MHHRC) successfully replicated this model, further confirming its validity as a best practice in SGBV service provision in the region.

Findings from the evaluation of this intervention indicated that police effectively provided EC. Over the life of the intervention, a total of 37 doses were administered to qualifying survivors of sexual assault by police at the two police stations without any adverse events. Most survivors reporting to the hospital for further care following referral were minors: $80 \%$ that reported from January to June 2012 were children aged 18 years and below. Police consistently provided referrals for survivors that presented at the police station, referring 49 cases to the hospital (from January to June 2012) for comprehensive care.

Transportation from the police stations to the hospital was noted as a barrier to referral uptake, however. Of the 49 cases referred to the hospital, 13 subsequently sought comprehensive care. Data from key informant interviews also suggested a tendency to redeploy officers trained in EC provision to perform other, 'core' police duties, such as public order management, thus possibly narrowing access to services for survivors. Recommendations from the study included: the need for SGBV to be better mainstreamed within police training and services; the need for child-friendly services to be integrated into all levels of care for SGBV survivors; and the need for concerted efforts to address transportation barriers in order to enhance the referral process between police and health facilities.

\section{Best Practice \#4: Decentralizing emergency medical responses for rape survivors to police (police provision of post-exposure prophylaxis [PEP])}

In collaboration with the Zambia Ministry of Health and Zambia Police Services (ZPS), the Population Council piloted the police provision of a PEP stat dose (3-day starter pack) for HIV prevention survivors reporting rape at police stations, coupled with the referral of these survivors for comprehensive care for sexual violence at a health facility.

The intervention involved sensitizing police officers on a range of issues relating to sexual violence, and on PEP and EC provision to survivors, with an emphasis on multi-sectoral approaches. Job aids were also developed to guide officers in determining PEP eligibility and referral, and communication and supply chain systems were established between the $\mathrm{MoH}$ and district pharmacy units, as well as between the ZPS hospital and the participating police stations.

Results from the evaluation of this intervention indicated that:

o 207 cases of sexual violence (all females) were reported at the participating police stations and police posts during the project period (November 2012 to October 2013).

0 Of these, $85 \%$ were girls under the age of 16 years, with the mean age of report being 13 years.

o The number of cases reported to the participating police stations increased by $56 \%$ between the $1^{\text {st }}$ and $4^{\text {th }}$ quarters of the project. 
o Of all cases, $65 \%(n=135)$ were reported within 72 hours of the incident. Of these, 31 were under 10 years old and therefore ineligible for PEP; these girls were referred directly to UTH for follow-up care.

o Police were able to provide eligible survivors with PEP without any adverse consequences

o $96 \%$ of survivors who reported to the police stations were given a medical referral report form, and $84 \%(n=173)$ were referred to the University Teaching Hospital (UTH).

o Only $2 \%(n=4)$ were accompanied to the hospital by a police officer, as stipulated by Zambia's National Guidelines for the Multidisciplinary Management of Survivors of GBV

Only a quarter of eligible survivors received PEP. Reasons for this include the fact that less than half of those reporting to police did so during police officers' official working hours. Victim Support Unit police officers were specifically trained for the provision of PEP, as they are mandated to attend to SGBV survivors. However, their working hours are limited to the 8 am to $5 \mathrm{pm}$ time period. Other plausible reasons include: the survivor presented when the police officer was on duty but away from his/her station; the survivor was already on antiretroviral therapy; the survivor or her family refused PEP; or the incident did not involve penetrative sex.

This study confirmed that Zambian police officers can effectively and correctly provide SV survivors with a three-day starter pack of PEP and refer them to health services for followup. However, the study also highlighted issues needed to improve program effectiveness, such as increasing access to PEP at police stations by modifying opening hours; expanding sensitivity training to other police officers (beyond Victim Support Unit officers alone); strengthening management and monitoring systems at police stations; decentralizing PEP delivery to primary health centers; and strengthening community-based responses to sexual violence cases, and to facilitate PEP access.

\section{Best Practice \#5: Establishing a 'Zero-Tolerance Village Alliance' against SGBV}

The Thohoyandou Victim Empowerment Programme's (TVEP's) Zero Tolerance Village Alliance (ZTVA) model involves mobilizing communities to take a collective stand against SGBV through educational workshops, dialogues, and campaigns within communities. Communities that are willing to undertake these activities and that meet certain criteria demonstrating their amenability toward fostering a 'zero-tolerant' environment are formally inducted into the 'Zero Tolerance Village Alliance' during a ceremony that includes a traditional pledge-taking rite (against SGBV) by traditional rulers and other male members of the community. Fostering such a 'zero tolerance' zone is designed to change social norms around violence in the communities concerned, and to address stigma around SGBV reporting.

Results from the evaluation of this model showed positive shifts in knowledge, attitude, and practices for both men and women across 83 independent variables (CI 95\%, p-value <0.001). SGBV reporting increased across intervention sites during and immediately following the 
intervention. Data collected 12 months after the intervention revealed a steady decline in rates of SGBV across 'Alliance' villages.

\section{Best Practice \#6: Using a school-based, comprehensive SGBV prevention model to address violence against children}

The Swaziland Action Group Against Abuse (SWAGAA) tested a school-based, 'Safe Spaces,' girls' empowerment intervention to help change SGBV knowledge, attitudes, and practices among in-school girls in Swaziland; enhance knowledge on other related health topics; improve girls' social assets and leadership skills; and increase girls' SGBV reporting. The intervention involved training young, female mentors to lead girls' clubs in-school, which served as safe spaces for girls to meet, form friendships, and enhance their SGBV knowledge and self-efficacy around falling victim to SGBV. An appropriate, SGBV-focused curriculum was also developed as part of the intervention.

The study findings showed very high levels of reported abuse among in-school girls in Swaziland: at endline, 34\% reported verbal sexual harassment by classmates; $40 \%$ reported experiencing physical abuse outside school, and $67 \%$ reported experiencing at least one form of SGBV. Study findings also demonstrated significant increases between baseline and endline in:

o The proportion of students that reported ever experiencing any form of SGBV either at school or in the community;

o Girls' social assets (e.g., having close friends and confidantes, and taking part in extracurricular activities);

o Positive changes in the attitudes of students with regard to SGBV in 13 out of 21 items used to measure these attitudes;

o Reporting about being subjected to sexual comments by fellow students, and awareness about other in-school girls being teased or subjected to verbal sexual harassment; and

o The proportion of girls that indicated that they would report incidents of sexual harassment by a student to teachers, school principal or the police.

There was, however, no significant change in the proportion of students that would report incidents of sexual harassment by a teacher. Furthermore, the interventions did not have any effect on the possibility that students would decline sexual advances from a student or teacher. The fact that the interventions did not have any effect on changing the possibility that students would decline sexual advances from either a teacher or student suggests that the model could be strengthened by incorporating components aimed at enhancing selfefficacy among girls. As the most common perpetrators of some kinds of abuse experienced by in-school girls were found in the wider community (strangers, other persons, male neighbours, male siblings, uncles, and fathers), integrating this tested model within the wider community would also be useful. 


\section{Result 2: South-South TA through a network of implementing partners}

The transition of the initiatives described above from pilots to actual best practices required focused efforts in the form of technical assistance (TA) between network partners in the global South between 2009 and 2013. During this period, the six partner projects were supported through Population Council expertise in areas such as intervention and research design, research proposal-writing, development of data collection tools, training of data collectors, monitoring of data collection, data analysis, report-writing, the design of advocacy and communication initiatives to promote the utilization of results, and the preparation of scientific presentation for delivery at high-impact regional and international conferences.

In addition to these efforts, four key TA activities were built in to the Network to foster peerto-peer learning in innovative and engaging ways: annual network meetings, partner exchange visits, the facilitation of internal networking, and the hosting and maintenance of a network website. These activities are described in further detail below.

\section{Annual network meetings}

On a yearly basis, the Council convened partners meetings to review implementation progress and provide a venue for South-South technical exchange. When possible, these meetings were held in conjunction with other regional or international SGBV events (such as the biennial SVRI Forum and the annual 16 Days of Activism Against Gender Violence) to increase their impact. Session topics were typically solicited from partners prior to the meeting to ensure that discussions were directly relevant to partners' needs. Issue-focused sub-groups were also formed to address special concerns such as responding to the needs of child survivors of SGBV, and new directions for the network. The annual network meetings also provided a platform for implementing partners to engage with non-project partners. Efforts were made annually to ensure that regional networks (such as SVRI and Raising Voices) and regional bodies (e.g., the East, Central and Southern Africa Health Community, SADC, and UNICEF/ESARO) participated to encourage South-South exchange on issues such as research and training, community-based prevention efforts, and adapting regional SGBV guidelines.

An overview of the annual network meetings held during the project period is provided in the Table below. Links to detailed reports of each meeting (with the meeting agenda, participants, and proceedings) are also included. 


\begin{tabular}{|c|c|c|c|c|}
\hline \multicolumn{5}{|c|}{ Overview of Annual Network Meetings } \\
\hline Year & Location & Objectives & \# of Participants & Meeting Report \\
\hline $\begin{array}{l}2011 \text { Feb } \\
7-9\end{array}$ & $\begin{array}{l}\text { Chisamba, } \\
\text { Zambia }\end{array}$ & $\begin{array}{l}\text { Facilitate South-South technical } \\
\text { exchanges and information sharing } \\
\text { among partners } \\
\text { Expose partners to emerging global } \\
\text { debates, resources, and research on } \\
\text { SGBV } \\
\text { Have partners showcase and exchange } \\
\text { their publications, IEC materials, } \\
\text { advocacy tools, etc. }\end{array}$ & 47 & $\begin{array}{l}\frac{\text { http://www.svri.org/S }}{\text { GBV2011NetworkMe }} \\
\text { etingReport.pdf }\end{array}$ \\
\hline $\begin{array}{l}2012 \text { June } \\
26-27\end{array}$ & $\begin{array}{l}\text { Mombasa, } \\
\text { Kenya }\end{array}$ & $\begin{array}{l}\text { Facilitate South-South technical } \\
\text { exchanges and information sharing on } \\
\text { the changing landscape of violence } \\
\text { among partners, donors, and other } \\
\text { experts over the life of the network } \\
\text { Reflect on the ways in which the } \\
\text { network's research is informing policy } \\
\text { and practice }\end{array}$ & 31 & $\begin{array}{l}\text { http://www.svri.org/S } \\
\text { GBVJune2012Annual } \\
\text { Meeting.pdf }\end{array}$ \\
\hline $\begin{array}{l}2013 \\
\text { Dec } 4\end{array}$ & $\mathrm{DC}, \mathrm{USA}$ & $\begin{array}{l}\text { Facilitate South-North technical } \\
\text { exchanges on SGBV in Africa } \\
\text { Build awareness of the network's } \\
\text { research and regional influence, highlight } \\
\text { priorities in SGBV research and } \\
\text { programming in East \& Southern Africa, } \\
\text { and foster collaborations in SGBV } \\
\text { among DC policy and program } \\
\text { audiences }\end{array}$ & 54 & $\begin{array}{l}\text { Forthcoming in } 2014 \\
\text { as a special edition of } \\
\text { a peer-review journal } \\
\text { (BMC Meeting } \\
\text { Abstracts) }\end{array}$ \\
\hline
\end{tabular}

\section{Partner exchange visits}

To promote more in-depth South-South technical assistance during the project period, partners were also given the opportunity to request exchange visits with other partner projects. This primarily involved learning visits to partner project sites, and on-site technical assistance as partners adopted the strategies they observed during their initial visits.

In February 2012, Kenyatta National Hospital had the opportunity to visit TVEP. As KNH is home to a one-stop center (the Gender-Based Violence Recovery Centre [GBVRC], where implementing partners tested an IPV screening intervention in 2012), $\mathrm{KNH}$ used this visit to learn from TVEP's one-stop services and systems. The visit deliberately coincided with the 'oath-taking' and village induction ceremony carried out by TVEP as a culmination of their intervention activities. This powerful ceremony (involving men such as traditional rulers and community leaders) was the end result of an elaborate community mobilization exercise on the part of TVEP. To create awareness about the GBVRC, KNH engages in community sensitization activities in Kenya. However, the IPV screening acceptability study showed a need to strengthen these activities in order to create a higher level of awareness of available 
SGBV services among survivors and the surrounding communities. The visit to TVEP inspired $\mathrm{KNH}$ to renew their efforts in this area.

In October 2012, the Population Council Zambia Office also paid a learning exchange visit to TVEP. As the work of both organizations has involved the provision of PEP to survivors and engagement with police, TVEP was considered an appropriate learning site. A representative from the Council's Zambia office spent time at: TVEP's newest ZTVA community; TVEP's trauma centers and Help Desks (to better understand the full range of services offered to survivors); TVEP's HIV cluster (to learn from the organization's means of following up on ARV 'defaulters,' and helping them resume treatment); and with TVEP's 'Access to Justice' team (to learn more about their follow-up procedures with survivors).

As the last partner to be incorporated into the network (and having experienced staff transitions earlier in the year) the Swaziland Action Group Against Abuse (SWAGAA) requested a visit to the Population Council's sites in Nairobi to learn first-hand from the Council's extensive experience with implementing and adapting 'safe spaces' models for inschool girls. This learning visit was conducted in October 2013 by SWAGAA's new Girls Empowerment Officer in charge of SWAGAA's intervention under the network. During the four-day visit, SWAGAA had the opportunity to visit and learn from 5 Population Council implementing partners in an urban settlement. The lessons learned from this visit on modalities for sustaining girls clubs, involving girls more deeply in running these clubs by themselves, and the role of financial literacy in mitigating SGBV will be used to strengthen SWAGAA's current program.

\section{Facilitating internal networking}

Maintaining communication among partners has been one of the most challenging aspects of the network. While partners are keen to contribute during in-person meetings, participation in virtual exchanges has been limited, due to time constraints and connectivity issues. Over the project period, internal information-sharing efforts have primarily consisted of direct partner communication by program staff, including distributing materials, tools, and publications. To encourage greater member interaction, a Facebook page was instituted in 2011, to facilitate more informal communication. This effort was not as successful as hoped, due to partners' preference for in-person engagement. In 2012, the Council started experimenting with Twitter, which is less time-consuming, for enhancing communication among partners. Although communication via email continues to be the preferred method among partners, the use of Twitter has served to expand the reach of the network and its resources. Between 2012 and 2013, the network nearly doubled its number of followers (from 36 to 61), representing a range of local, national, and international organizations around the world. Due to the use of Twitter to create visibility for the network, the project director was also recently recognized by The Guardian as one of the Top 10 Tweeters on Sexuality and Development, who are shaping policy and practice (http://www.theguardian.com/global-development-professionalsnetwork/2014/feb/04/top-10-tweeters-on-sexuality-and-development). 


\section{Website maintenance and hosting}

From November 2009 to December 2013, the program's collaboration with the Sexual Violence Research Initiative (SVRI) on the network's website (www.svri.org/popcouncil.htm) continued to be strategic, high-profile, and beneficial. Accessible from the SVRI homepage, the network's website served as a central repository for partner products and other resources generated by network partners over the life of the program. As a leading SGBV resource, the SVRI website also regularly used its international Twitter base to publicize emerging work from the network among its followers. These tweets were also highlighted on SVRI's homepage. New resources generated by the program were featured on SVRI's influential listserv as well. These efforts played a role in the number of hits received by the program from year to year (see Figure 1 below). Furthermore, the network webpage was updated regularly with new documents throughout the project period, with nearly 50 posted to date.

Figure 1 shows an annual increase in project page views, apart from in the year 2013, which was a no-cost extension year with fewer project activities.

Figure 1: Annual project website views

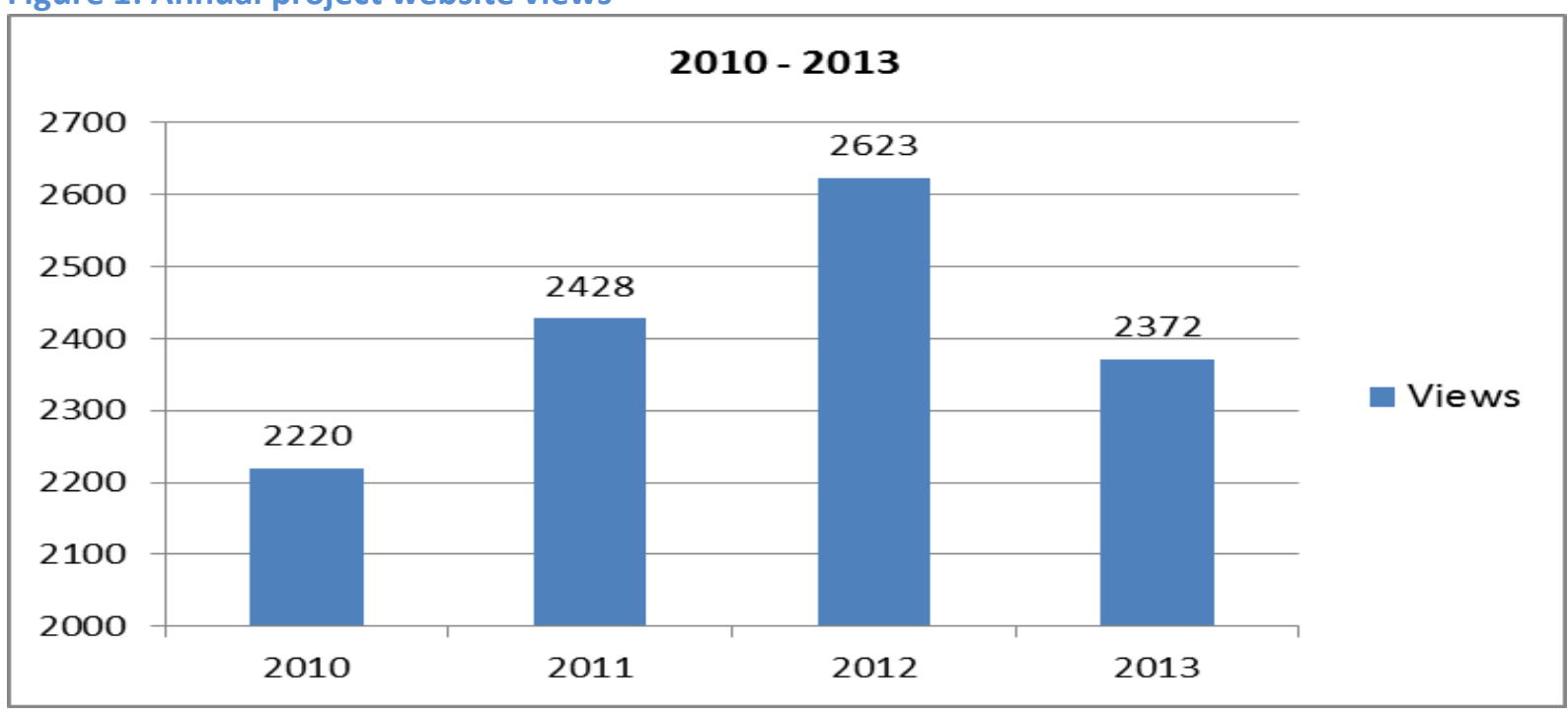

\section{Result 3: Policy and programs influenced through the dissemination of best practices to key audiences}

The ultimate purpose of the program was to influence policy and practice by developing and disseminating a strong, regionally-relevant evidence base in the form of the best practices described in previous sections. Although best practices can be slow to spread, they tend to do so after a success has been demonstrated. Even then, a lack of knowledge about current best practices, a lack of motivation to make changes involved in their adoption, and a lack of knowledge and skills required to do so are key barriers to adopting best practices. ${ }^{1}$

\footnotetext{
${ }^{1}$ Rouse, M. (2007). Definition: Best practice. Retrieved from: http://searchsoftwarequality.techtarget.com/definition/best-practice.
} 
Thus, over the life of the program, Council staff remained actively engaged in regional and international SGBV dialogues, and widely shared the program's evidence (see Appendix 1 for a detailed list of network presentations and publications). These efforts influenced policy and programs in the region in myriad ways, as highlighted in this section.

\section{Regional Bodies}

\section{East African Community}

The Council actively collaborated with the East African Community (EAC) to organize the first-ever symposium dedicated specifically to SGBV at the $4^{\text {th }}$ EAC Health and Scientific Conference which took place in Kigali, Rwanda from March 27-29, 2013. This regional conference aimed to consolidate regional health priorities and opportunities among EAC Member States and partners. The symposium, entitled 'Toward a Multi-Sectoral and Comprehensive Response to SGBV in East Africa,' sought to share emerging lessons from Phase II of the program in order to stimulate regional dialogue and action on the interrelated issues of HIV \& AIDS and SGBV through a comprehensive, multi-sectoral, approach. In addition to EAC Member States, the meeting brought together SGBV experts in research, policy, practice and advocacy; legislation, health and social services; and prevention, care and rehabilitation.

In recognition of the important work carried out under this program, the East African Community solicited presentations from every partner represented in the network. The Council worked with these implementing partners to ensure they submitted the solicited presentations, and supported their attendance of the conference. The Council also provided technical assistance to the EAC for organizing the symposium, and made a financial contribution towards the conference, ensuring that government officials from across the region participated in the symposium as presenters on SGBV, for instance. The symposium culminated in a number of recommendations, by attendees, for resolutions, presented below:

1. The provision, by the EAC Secretariat, of a framework for a multi-sectoral response to SGBV in the region

2. Sustained advocacy at national and regional levels to hold Member States accountable for resource allocation

3. SGBV mainstreaming across sectors

4. Auditing and review of harmful, gender-blind clauses in policies and laws

5. Male engagement and involvement in the prevention of, response to, SGBV (including SGBV against males)

6. Capacity-building of range of providers (health, police, justice, social services, education, etc.) to address the needs of child survivors of SGBV

In 2014, these resolution recommendations will be presented to the relevant sectoral Councils within the EAC for consideration. The outcomes of this process will then be 
presented to Ministers of relevant Health, Ministers of Gender, and other relevant Ministers in the East African Community.

\section{East, Central and Southern Africa Health Community}

The network has had a long-standing and successful relationship with the East, Central and Southern Africa Health Community (ECSA-HC). As an intergovernmental body, ECSA-HC was mandated to focus on SGBV, including child sexual abuse (CSA), through resolutions at its 2006 and 2009 annual Health Ministers' Conferences. Project staff actively engaged with ECSA-HC to help operationalize these resolutions. In 2010, this work focused three products: a literature review on child sexual abuse (CSA) in the region; guidelines for clinical management of CSA; and a comprehensive advocacy strategy. The literature review objectives were: creating understanding of the magnitude and nature of CSA in the ECSA region; raising awareness about CSA in the region; and informing sector policy and program responses, for prevention and management. The advocacy strategy is intended to: increase awareness and dialogue at all levels about CSA and its negative consequences; advocate for action at the national level to surpass ratification of international rights and treaties and enact and enforce legislation on all forms of violence; advocate for harmonization of laws and procedures promoting and protecting children's rights; and increasing regional, national, and local resources (financial, human, material) for implementing laws, policies, and programs needed for integrated CSA prevention and response.

In 2011, the Council provided support to ECSA-HC for extracting lessons from its CSA work to communicate to the highly-visible, high impact 2011 SVRI Forum. In 2012, ECSA-HC received technical and financial support from the Population Council to convene a meeting of its Member States to help identify and prioritize regional SGBV advocacy concerns, and developing country-specific SGBV advocacy plans to feed into a comprehensive, regional plan. In 2013, the ECSA-HC received further technical and financial support to partner with selected Member States (Kenya, Malawi, and Mauritius) in operationalizing aspects of their advocacy plans.

Specifically, ECSA-HC collaborated with the Kenyan and Malawi governments to convene one meeting each, centering on advocacy for resource allocation for SGBV and CSA by governments. Each meeting generated important ideas to encourage resource allocation by African governments for SGBV - e.g., development partners being more proactive by engaging in government budget cycles early on so that SGBV issues are highlighted and budgeted for; learning lessons from the strategies used to establish budget lines for other reproductive health issues in Kenya and Malawi, such as family planning and HIV and AIDS; and engaging more closely with parliamentarians who can ensure that SGBV/CSA issues are brought to the parliamentary floor for debate, thus ensuring that these issues gain more government attention. ECSA-HC also collaborated with the Government of Mauritius to convene a meeting of stakeholders to advocate for the integration of perpetrator rehabilitation measures into the prevention and management programs of the SGBV response in Mauritius. A draft strategic framework for the rehabilitation of the perpetrators was devised in the course of this meeting. 


\section{UNHCR Regional Support Hub}

Project staff actively engaged with strategic regional bodies to strengthen SGBV dialogue and action in the region. In 2013, the Council engaged extensively with UNHCR's Regional Support Hub to promote the utilization of project results among refugee populations. These efforts led to a collaborative project between the Council and UNHCR, coupled with funding from the MacArthur Foundation to replicate and test selected network models in refugee settings in Uganda (i.e., routine SGBV screening and the ZTVA model). Results from this initiative are expected to inform programming within UNHCR country offices and among UNHCR implementing partners in the region.

\section{UNICEF Eastern and Southern Africa Regional Office (ESARO)}

Recognizing the Council's thought leadership and the network's contributions in the area of SGBV, UNICEF ESARO solicited a commentary from the Council for publication in Research Watch - a UNICEF publication which seeks to share and analyze new research and the views of leading thinkers on critical issues for children. Project staff developed a commentary on this issue in 2013, drawing on network findings, in order to generate perspectives and debate on violence against children and move the field forward. The published volume, entitled 'Violence against Children - What Approaches Work?', targeted development field staff, decision-makers and donors, and was widely disseminated through UNICEF offices; the websites of UNICEF partners, the Population Council, and the SVRI; and media. The commentary may be accessed here: http://www.unicef-irc.org/research-watch/Violenceagainst-children--a-silent-threat/987/, while the complete volume of this Research Watch edition may be accessed here: http://www.unicef-irc.org/research-watch/Violence-againstchildren--a-silent-threat/commentary.html.

\section{World Health Organization}

During the project period, the World Health Organization (WHO) reached out to project staff, requesting the Council's participation in a meeting of researchers on IPV to discuss the current knowledge in the field and to develop strategies for improving interventions to reduce IPV among pregnant women in developing countries. Project staff also provided input into a forthcoming WHO Handbook on IPV screening in developing country settings. The draft Handbook currently cites the IPV screening model tested under this program.

\section{National and Local Bodies}

The best practices tested under this program had a remarkable influence on national and local programming and policy, as well as on donor funding decisions. These processes are documented in detail in Appendix 2 for each partner under the network. 


\section{Program Challenges}

Given its strong focus on South-South technical assistance, the program was essentially structured to attend to the challenges that would normally be encountered in a multicountry initiative. Consequently, many of the 'challenges' experienced by the program were viewed as opportunities to build capacity and were handled as project activities. The program began with the expectation that partners would require technical support for a range of activities. These activities were successfully implemented with technical support from the Population Council, as described earlier in this report. By the end of the program, a number of network partners had strengthened their capacity to the point of being able to build the capacity of other organizations to implement tested interventions, for instance. The challenge encountered under the network therefore had more to do with ensuring the maintenance of a coherent, regional program, despite the varying levels of capacity within various countries represented within the network. The variety of technical assistance approaches used under the network made this possible.

The technical support needs of some regional bodies also presented a challenge. Although regional bodies may be willing to support SGBV-related agendas, experience under the program demonstrated that the capacity to organize this sort of support is sometimes lacking due to staffing shortages or to gaps in technical capacity. The time and effort required to adequately provide this kind support may have been underestimated, but the program allowed project staff to invest this time and effort, with several positive outcomes in the end.

\section{Conclusion}

Over the years, the Expanding the Evidence Base on Comprehensive Care for Survivors of Sexual Violence in Sub-Saharan Africa program enabled partners in East and Southern Africa to collectively test and document experiences, develop cost-effective responses to SGBV, and avoid the duplication of effort. Furthermore, the strength of the Africa Regional SGBV Network gained recognition by other donors and partners during the program period. The technical assistance that forms an integral part of 'the Network approach' (through proposal and presentation development, remote and on-site support for research and programs, partner exchange learning visits, etc.) was a key aspect of the added value brought by the Network approach.

Between the project commencement and end dates, there was heightened interest from donors and regional bodies in applying and testing aspects of the Network approach applied in different settings. Discussions with partners and other stakeholders during the project period highlighted several possibilities for replicating the current approaches of the network:

o Regional replication of individual project models that have been successfully tested through the Network in a national setting; 
o Replicating hybridized versions of existing Network interventions for roll-out across countries;

o Replicating a common intervention, based on tested Network responses that can be piloted regionally;

o Replicating tested Network responses among new populations (e.g., children, refugees) on a regional level;

o Replicating certain aspects of the Network approach regionally (e.g., components of the South-South technical assistance model to continually build capacity and Network strength); and

o Replicating influencing models that Network partners have successfully employed to inform policy and practice regionally.

The donor interest that became apparent during the project period was eventually backed by donor funding (from the MacArthur Foundation) before the end of the project period, geared toward testing network approaches with refugee populations; replicating the SouthSouth technical assistance model to build the capacity of UNHCR implementing partners as well as network strength; and replicating influencing models used under the network to inform programming within UNHCR country offices in the region. Further funding from other donors has also been issued at the partner level in some countries, as outlined in Appendix 2.

Activities during the 4-year project period demonstrated that the face-to-face forms of South-South interaction characteristic of the Africa Regional SGBV Network were viewed as being unique, and were of paramount importance to partners. Partners cited myriad examples of being inspired to take action in their individual countries after being afforded undistracted time and space to learn about other partners' work (through annual partner meetings, exchange visits, etc.), and to realize what is doable in their own settings.

In the words of one network partner:

There's something about interacting with the Network that inspires partners to push for similar things in their countries after they've compared themselves to other countries. There's more of a 'how-to' approach with this Network. It's much more practical so that partners are able to benchmark themselves against what's happening regionally - and it's hard to really do that without this sort of network structure that we have. Without this Network, one tends to think one is doing enough, [or that] one is doing it right.

In summary, the exchanges (including technical assistance among partners, annual partner meetings, partner exchange visits, and other learning opportunities) made possible through the Network's approach were seen as setting it apart markedly from other approaches. The Network approach has proven to be an efficient, non-duplicative means of generating a coherent body of multi-sectoral evidence on SGBV in the region within a similar time frame. Given the experience garnered by the program over the years, the network is currently considered as a resource to the region, with strengths in 1) providing technical assistance in intervention development, research, training, and influencing policy and practice; 2) 
replicating responses to SGBV that have been tested by partners, and 3) testing out new, innovative responses to SGBV. 


\section{Appendices}

Appendix 1: Reports and Papers Published and Presented under the Expanding the Evidence Base on Comprehensive Care for Survivors of Sexual Violence in Sub-Saharan Africa Program

\section{3}

\section{Technical Reports and Published Papers}

ECSA-HC \& Population Council (2013). Scaling up advocacy for gender-based violence and child sexual abuse in the East, Central and Southern Africa Health region. Arusha, Tanzania: ECSA-HC.

SWAGAA (2013). Effectiveness of a comprehensive sexual and gender-based violence prevention project for in-school girls in Swaziland. SWAGAA: Manzini, Swaziland.

Thompson, J. (2013). 'Using evidence to make change happen': Strategies and learning from the Africa Regional SGBV Network. Nairobi: Population Council.

Thompson, J., Undie, C., Askew, I. (2013). Access to emergency contraception and safe abortion services for survivors of rape and defilement in sub-Saharan Africa: A regional overview. Nairobi: Population Council.

Undie, C., Maternowska, M.C., Mak'anyengo, M., Askew, I. (2013). Feasibility of routine screening for intimate partner violence in public health care settings in Kenya. Nairobi: Population Council.

Undie, C. (2013). Toward a research agenda on gendered violence in sub-Saharan Africa. Ethnicity and Health 18(5): 449-453.

Undie, C. (2013). Why we need to think about sexuality and sexual Well-being: Addressing sexual violence in sub-Saharan Africa. In (eds.) Andrea Cornwall, Susie Jolly, Kate Hawkins. Women, sexuality and the political power of pleasure. London: Zed Books.

Undie, C., Mullick, S., and Askew, I. (2013). The missing 'C': Sexual violence against children in sub-Saharan Africa. Research Watch, UNICEF.

Zama, M., Price, J., Topp, S., and Keesbury, J. (2013). Mitigating the consequences of sexual violence in Zambia by decentralizing emergency medical responses to Police Victim Support Units: Report on the feasibility of police provision of PEP for HIV in Zambia. Lusaka: Population Council.

\section{Conference Presentations}

Undie, C., Mak'anyengo, M., Maternowska, C. (2013). Using an IPV screening tool in public health care settings in Kenya: An innovative approach to improving the quality of maternal health care. Oral presentation at the Global Maternal Health Conference, Arusha, Tanzania, January 2013. 
Mak'anyengo, M., Undie, C., Maternowska, C. (2013). A summary of the IPV screening feasibility study, Kenyatta National Hospital. Oral presentation at the United States Institute of Peace International Symposium on The Missing Peace: Sexual Violence in Conflict and PostConflict Settings, Washington DC, USA, February 2013.

Ajema, C. \& Mukoma, W. (2013). Improving the collection, documentation, and utilization of medico-legal evidence in Kenya. Oral presentation at the $4^{\text {th }}$ East African Community Health and Scientific Conference, Kigali, Rwanda, March 2013.

Denis, M., Zama, M., Price, J. (2013). Assessing the feasibility of improving access to HIV PEP for SV survivors through Zambian Police Services. Oral presentation at the $4^{\text {th }}$ East African Community Health and Scientific Conference, Kigali, Rwanda, March 2013.

Gawani, C. (2013). Testing the feasibility of police provision of emergency contraception in Malawi. Oral presentation at the $4^{\text {th }}$ East African Community Health and Scientific Conference, Kigali, Rwanda, March 2013.

Katende, M.J. (2013). HIV and AIDS: Regional perspectives. Oral presentation at the $4^{\text {th }}$ East African Community Health and Scientific Conference, Kigali, Rwanda, March 2013.

Kilonzo, N. et al. (2013). Overview of GBV and HIV: Regional and international perspectives. Keynote speech at the $4^{\text {th }}$ East African Community Health and Scientific Conference, Kigali, Rwanda, March 2013.

Mallya, G. \& Malaki, B. (2013). Status of SGBV and HIV and AIDS interventions in Tanzania. Oral presentation at the $4^{\text {th }}$ East African Community Health and Scientific Conference, Kigali, Rwanda, March 2013.

Mak'anyengo, M., Undie, C., Maternowska, C. (2013). Screening for intimate partner violence in public health care settings in Kenya: Lessons from the East African Region. Oral presentation at the $4^{\text {th }}$ East African Community Health and Scientific Conference, Kigali, Rwanda, March 2013.

Ministry of Health, Burundi (2013). The status of SGBV and HIV and AIDS interventions in Burundi. Oral presentation at the $4^{\text {th }}$ East African Community Health and Scientific Conference, Kigali, Rwanda, March 2013.

Ministry of Health, Uganda (2013). SGBV and HIV interventions in Uganda. Oral presentation at the $4^{\text {th }}$ East African Community Health and Scientific Conference, Kigali, Rwanda, March 2013.

Ministry of Health, Zanzibar (2013). The status of SGBV and HIV and AIDS interventions in Zanzibar. Oral presentation at the $4^{\text {th }}$ East African Community Health and Scientific Conference, Kigali, Rwanda, March 2013.

Mukasine, C. (2013). GBV and child abuse: A public health issue in Rwanda. Oral presentation at the $4^{\text {th }}$ East African Community Health and Scientific Conference, Kigali, Rwanda, March 2013.

Nyoni, N. (2013). Testing the feasibility and effectiveness of a comprehensive sexual and gender-based violence prevention project for in-school girls in Swaziland. Oral presentation at the $4^{\text {th }}$ East African Community Health and Scientific Conference, Kigali, Rwanda, March 2013.

Odongi, E. (2013). Sexual and gender-based violence and HIV and AIDS in Kenya. Oral presentation at the $4^{\text {th }}$ East African Community Health and Scientific Conference, Kigali, Rwanda, March 2013. 
Undie, C. (2013). Symposium on HIV \& AIDS and SGBV: Introduction. Oral presentation at the $4^{\text {th }}$ East African Community Health and Scientific Conference, Kigali, Rwanda, March 2013.

Keke, X. (2013). Long-term psychosocial support for survivors of sexual violence: A literature review. Oral presentation at the $6^{\text {th }}$ South African AIDS Conference, Durban, South Africa, June 2013.

Carty, C., Nicholson, F., et al. (2013). Patriarchal villages in South Africa mobilized to break the cycle of endemic and culturally-sanctioned human rights abuses: A structured intervention with sustained SGBV impacts. Poster presentation at the International AIDS Conference, Kuala Lumpur, Malaysia, July 2013.

Olielo, J. 2013. Sharing experiences on GBV tools used in RH service delivery settings. Oral presentation at the Government of Mauritius and ECSA Health Community's 'Advocating for integrating the rehabilitation of perpetrators into the prevention and management programs of SGBV and CSA response' Meeting, Port Louis, Mauritius, July 2013.

Olielo, J. 2013. Addressing the issue of SGBV perpetrators in the ECSA region. Oral presentation at the Government of Mauritius and ECSA Health Community's 'Advocating for integrating the rehabilitation of perpetrators into the prevention and management programs of SGBV and CSA response' Meeting, Port Louis, Mauritius, July 2013.

Ajema, C., Mukoma, W. et al. (2013). Utilization of a locally-assembled rape kit in management of sexual violence in low-resource settings. Case study of Kenya. Oral presentation at the 2013 Sexual Violence Research Initiative (SVRI) Forum, Bangkok, Thailand, October 2013.

Carty, C. (2013). Culturally-sanctioned SGBV as a driver for child perpetration of assault in regions of traditional leadership in Limpopo, South Africa. Oral presentation at the upcoming 2013 SVRI Forum, Bangkok, Thailand, October 2013.

The Thohoyandou Victim Empowerment Programme (2013). The impact of public oathtaking ceremonies on SGBV reporting: Results from two traditional leadership villages in South Africa. Oral presentation at the upcoming 2013 SVRI Forum, Bangkok, Thailand, October 2013.

Thompson, J., Undie, C., Askew, I. (2013). Access to emergency contraception and safe abortion services for survivors of rape and defilement in sub-Saharan Africa: A regional overview. Oral presentation at the 2013 SVRI Forum, Bangkok, Thailand, October 2013.

Undie, C., Mak'anyengo, M., Maternowska, M.C., Askew, I. (2013). Feasibility of routine screening for intimate partner violence in public health care settings in Kenya. Oral presentation at the 2013 SVRI Forum, Bangkok, Thailand, October 2013.

Undie, C., Mak'anyengo, M., Maternowska, M.C., Askew, I. (2013). Feasibility of routine screening for intimate partner violence in public health care settings in Kenya. Poster presentation at the 2013 SVRI Forum, Bangkok, Thailand, October 2013.

Undie, C., Mak'anyengo, M., Maternowska, M.C., Askew, I. (2013). Feasibility of routine screening for intimate partner violence at Kenyatta National Hospital. Oral presentation at Kenyatta National Hospital, Nairobi, Kenya, October 2013.

Undie, C., Mak'anyengo, M., Maternowska, M.C., Askew, I. (2013). Feasibility of routine screening for intimate partner violence in public health care settings. Solicited presentation at Liverpool VCT, Care, and Treatment, Kenya, November 2013. 
Ajema, C. \& Mukoma, W. (2013). Improving the collection, documentation, and utilization of medico-legal evidence in Kenya. Oral presentation at the 1st Washington, DC Meeting of the Africa Regional SGBV Network, Washington, DC, USA, December 2013.

Carty, C., Nicholson, F., Hadebe, T. (2013). The Zero Tolerance Village Alliance Model in South Africa. Oral presentation at the $1^{\text {st }}$ Washington, DC Meeting of the Africa Regional SGBV Network, Washington, DC, USA, December 2013.

Manzini-Henwood, C. (2013). Development of national guidelines for a multisectoral response to SGBV for adults and children in Swaziland. Oral presentation at the $1^{\text {st }}$ Washington, DC Meeting of the Africa Regional SGBV Network, Washington, DC, USA, December 2013.

Shanampota, J., Zama, M., Price, J. (2013). Mitigating the consequences of sexual violence by decentralizing emergency medical responses: Feasibility study on police provision of postexposure prophylaxis for HIV (PEP) in Zambia. Oral presentation at the $1^{\text {st }}$ Washington, DC Meeting of the Africa Regional SGBV Network, Washington, DC, USA, December 2013.

Mak'anyengo, M., Undie, C., Maternowska, M.C., Askew, I. (2013). Feasibility of routine screening for intimate partner violence in public health care settings in Kenya. Oral presentation at the $1^{\text {st }}$ Washington, DC Meeting of the Africa Regional SGBV Network, Washington, DC, USA, December 2013.

\section{2}

\section{Technical Reports and Published Papers}

Ajema, C., Mukoma, W., Mugyenyi, C., Meme, M., Kotut, R., Mulwa, R. (2012). Improving the collection, documentation and utilization of medico-legal evidence in Kenya: Research Brief. LVCT: Nairobi, Kenya.

Ajema, C., Mukoma, W., Mugyenyi, C., Meme, M., Kotut, R., Mulwa, R. (2012). Improving the collection, documentation and utilization of medico-legal evidence in Kenya. LVCT: Nairobi, Kenya.

Carty, C., Nicholson, F. (2012). Zero Tolerance Village Alliance intervention model: Evaluation and report, 2010-2012. TVEP: South Africa.

ECSA Health Community (2012). Special Edition of the ECSA Bulletin on Sexual and Gender-Based Violence.

Keesbury, J., Onyango-Ouma, W., Undie, C., Maternowska, C. et al. (2012). A review and evaluation of multi-sectoral response centers ('one-stop centers') for gender-based violence in Kenya and Zambia. Population Council: Nairobi, Kenya.

LVCT, WHO, SVRI (2012). Strengthening GBV and HIV response in sub-Saharan Africa. LVCT: Kenya.

MHRRC, MPS, MOH (2012). Testing the feasibility of police provision of emergency contraception in Malawi. MHRRC: Malawi. 
Njuki, R., Okal, J., Warren, C.E., Obare, F., Abuya, T., Kanya, L., Bellows, B., Undie, C., Askew, I. (2012). Exploring the effectiveness of the output-based aid voucher program to increase uptake of gender-based violence recovery services in Kenya: A qualitative evaluation. BMC Public Health (12) 426.

Population Council, Kenya (2012). The Africa Regional Sexual and Gender-Based Violence Network Annual Partners Meeting: June 26-27 2012, Mombasa, Kenya: Meeting Report. Population Council: Nairobi, Kenya.

Thompson, J. and Nkweto Simmonds, F. (2012). A review of statutory sentencing provisions for rape, defilement, and sexual assault in East, Central, and Southern Africa. Population Council: Nairobi.

Undie, C., Maternowska, C., Mak'anyengo, M., Keesbury, J., Askew, I. (2012). Routine screening for IPV in public health care settings in Kenya: An assessment of acceptability. APHIA II OR Project in Kenya/ Population Council: Nairobi, Kenya.

Undie, C. (2012). Why we don't screen for intimate partner violence in sub-Saharan Africa ... and why we must. RH Reality Check.

\section{Conference Presentations}

Mak'anyengo M, Undie, C., Maternowska, C. Screening for IPV at Kenyatta National Hospital. Kenya Psychiatric Association Annual Scientific Conference, Kisumu, Kenya, July 12-13, 2012.

Askew I. 'State of the evidence: What are the research gaps and priorities for driving forward the GBV/HIV agenda in sub-Saharan Africa.' Solicited presentation at the LVCT, WHO, and SVRI Workshop on Strengthening GBV \& HIV Integration and Responses in sub-Saharan Africa. Nairobi, Kenya, July 30-31, 2012.

Undie C., Maternowska C., Mak'anyengo. 'Acceptability and feasibility of GBV screening and responses in health care settings.' Solicited presentation at the LVCT, WHO, and SVRI Workshop on Strengthening GBV \& HIV Integration and Responses in sub-Saharan Africa. Nairobi, Kenya, July 30-31, 2012.

Manzini-Henwood C, Mhlungu L. How safe are our schools for girls?: Findings from a baseline survey. ' Solicited presentation at the International Conference on Gender-Based Violence. Nairobi, August 1-3, 2012.

Nicholson F. 'The Zero Tolerance Village Alliance.' Solicited presentation at the International Conference on Gender-Based Violence. Nairobi, August 1-3, 2012.

Undie C., Maternowska C., Mak'anyengo M, Askew I. 'Screening for IPV at Kenyatta National Hospital: An assessment of acceptability.' Solicited presentation at the International Conference on Gender-Based Violence. Nairobi, August 1-3, 2012.

Zama M, Price J, Topp S. 'Assessing the feasibility of improving access to HIV PEP for sexual violence survivors through Zambian Police Services.' Solicited presentation at the International Conference on Gender-Based Violence. Nairobi, August 1-3, 2012. 
Undie C. et al. 'Integrating screening for violence against women and children into HIV and primary health care services in East Africa: An innovation for improving maternal and child health outcomes.' Pre-formed panel presentation at the ECSA-HC's 6 ${ }^{\text {th }}$ Best Practices Forum in Health, Arusha, Tanzania, August 14-17, 2012.

Undie C. et al. 'Emerging evidence for integrating screening for violence against women and children into HIV and primary health care services in East Africa. Pre-formed panel presentation at the Integration for Impact Conference.' Nairobi, Kenya, September 12-14, 2012.

Undie, C. 'Early marriage: A program intervention supporting adolescent girls in Nyanza Province, Kenya.' Solicited presentation at the UNHCR Child Protection \& SGBV Workshop, Nairobi, Kenya, October 3, 2012.

Undie, C. (2012). Empowering married girls: Synopsis of a program intervention supporting married girls in Nyanza Province, Kenya. Solicited presentation as a discussant at the Girls Not Brides (Global Partnership to End Child Marriage) $1^{\text {st }}$ Regional Strategic Planning Meeting in SSA, Johannesburg, South Africa, November 6-7, 2012

Undie C., Maternowska C., Mak'anyengo. 'Screening for IPV at Kenyatta National Hospital, Kenya.' Solicited presentation at the World Health Organization Researchers Meeting. Geneva, November 13-15, 2012.

Undie C. 'Interventions and tools to respond to SGBV and child sexual abuse in the ECSA region: Evidence and practice.' ECSA-HC Research, Information \& Advocacy Expert Committee Meeting (Pre-Conference to the 56 ${ }^{\text {th }}$ ECSA-HC Health Ministers Conference). Arusha, Tanzania, December 11-12, 2012.

Undie C. 'Demystifying advocacy: Lessons from the ECSA region.' ECSA-HC Research, Information \& Advocacy Expert Committee Meeting (Pre-Conference to the 56 th ECSA-HC Health Ministers Conference). Arusha, Tanzania, December 11-12, 2012.

\section{1}

\section{Technical Reports and Published Papers}

Raifman, S., Askew, I., Amin, S., Keesbury, J., Mullick, S., Diers, J., Budiharsana, M., Undie, C., Zama, M., Menziwa, M., Hutchinson, S., Rutenberg, N. 2011. The prevention and management of HIV and sexual and gender-based violence: Responding to the needs of survivors and those-at-risk. Washington, DC: Population Council.

TVEP. 2011. No Excuse for Abuse: A History of the Thohoyandou Victim Empowerment Program. January 2011. Sibasa, South Africa: Thohoyandou Victim Empowerment Program.

Population Council. 2011. Comprehensive Responses to Sexual Violence in East and Southern Africa: Lessons Learned from Implementation. May 2011. Lusaka: Population Council. 


\section{Conference Presentations}

Undie, C., Maternowska, C. and M. Mak'anyengo. "Acceptability of routine screening for IPV in public health care settings in Kenya." Presentation at the Program Dialogue for Stakeholders on Screening for IPV in Public Health Care Settings in Kenya. Nairobi, September 8, 2011.

Undie, C., Maternowska, C. and M. Mak'anyengo. "Screening for intimate partner violence at Kenyatta National Hospital: What do women think? What do women want?" Oral presentation at Kenyatta National Hospital Annual Scientific Conference. October 13-14, 2011.

Keesbury, J., Wilson, K., Chileshe, D., Moono, H. and S. Makashyini. "Assessing schoolbased sexual violence In Zambia: A baseline knowledge, attitudes, and practices survey in eight schools to evaluate "Our Girls Our Future: Building Synergies To End Abuse Against Girls In Zambia. Oral presentation at the Sexual Violence Research Initiative (SVRI) Forum 2011, Cape Town, South Africa, October 10-13, 2011.

Maternowska, C. "Child-friendly models for prevention and response to violence in East and Southern Africa." Oral presentation at Sexual Violence Research Initiative (SVRI) Forum 2011, Cape Town, South Africa, October 10-13, 2011.

Gawani, C. "Testing the feasibility of police provision of emergency contraception in Malawi." Oral presentation at Sexual Violence Research Initiative (SVRI) Forum 2011, Cape Town, South Africa, October 10-13, 2011.

Simbaya, J. "An assessment of cost and model effectiveness of One-Stop Centre response models for gender-based violence in Zambia." Oral presentation at the Sexual Violence Research Initiative (SVRI) Forum 2011, Cape Town, South Africa, October 10-13, 2011.

Undie, C., Maternowska, C. and M. Mak'anyengo. "Screening for intimate partner violence in public health care settings in Kenya: What do women think? What do women want?" Oral presentation at Sexual Violence Research Initiative (SVRI) Forum 2011, Cape Town, South Africa, October 10-13, 2011.

Undie, C. "The situation 'on the ground': Work on gender-based violence. Tools and ideas for dialogue: What works and what doesn't." Invited presentation at SIDA Dialogue on Rights Meeting. Pretoria, South Africa. November 7-8, 2011.

Manzini-Henwood, C. "Assessing school-based sexual violence in Swaziland: A baseline knowledge, attitudes and practices survey in two schools to evaluate a girls' empowerment intervention in Swaziland." Poster presentation at Sexual Violence Research Initiative (SVRI) Forum 2011, Cape Town, South Africa, October 10-13, 2011.

Nare, P. “The Zero Tolerance Village Alliance: Baseline survey report." Poster presentation at Sexual Violence Research Initiative (SVRI) Forum 2011, Cape Town, South Africa, October 10-13, 2011.

Ajema, C. "Documentation challenges in the delivery of Post Rape Care Services using an Integrated Service Delivery Approach." Poster presentation at the Sexual Violence Research Initiative (SVRI) Forum 2011, Cape Town, South Africa, October 10-13, 2011.

Odongo, O. "Sub-Saharan Africa responds to Child Sexual Abuse: Literature review to inform policies on response - Findings from Anglophone and Francophone Africa, 2000- 
2010." Poster presentation at Sexual Violence Research Initiative (SVRI) Forum 2011, Cape Town, South Africa, October 10-13, 2011.

Simmonds, F. "Getting 'tough' on sex offenders: Implementing minimum sentences in lowresource settings." Poster presentation at Sexual Violence Research Initiative (SVRI) Forum 2011, Cape Town, South Africa, October 10-13, 2011.

Keesbury, J. "The 'three delays' in responding to gender-based violence." Poster presentation at Sexual Violence Research Initiative (SVRI) Forum 2011, Cape Town, South Africa, October 10-13, 2011.

Zama, M. "Assessing the feasibility of Post-Exposure Prophylaxis (PEP for HIV prevention) for rape survivors at police facilities in Zambia." Poster presentation at Sexual Violence Research Initiative (SVRI) Forum 2011, Cape Town, South Africa, October 10-13, 2011.

\section{0}

\section{Technical Reports and Published Papers}

Keesbury, Jill and Ian Askew. 2010. Comprehensive Responses to Gender Based Violence in Low-Resource Settings: Lessons Learned from Implementation. Lusaka: Population Council.

Elson, Lynne and Jill Keesbury. 2010. PEPFAR Special Initiative on Sexual and GenderBased Violence: Baseline Report. Lusaka: Population Council.

Keesbury, Jill and Jill Thompson. 2010. A step-by-step guide to strengthening sexual violence services in public health facilities: Lessons and tools from sexual violence services in Africa. Lusaka: Population Council.

\section{Conference Presentations}

Amin, Sajeda. May 2010. "Measurement issues in programs for GBV prevention and services: Assessing output and outcomes." Invited presentation, Consultation for Scaling up Response to Gender-Based Violence in PEPFAR, Washington, DC.

Keesbury, Jill et al. June 2010. “The Copperbelt Model of Integrated Care." Oral presentation at Global Health Conference, Washington, DC.

Keesbury, Jill and Lynne Elson. July 2010. "Health Care Providers in Uganda and Rwanda are Knowledgeable about Sexual Violence and HIV, but Few are Equipped to Provide Comprehensive Services." Poster presentation at XVII International AIDS Conference in Vienna, Austria.

Keesbury, Jill and Jill Thompson. December 2011. “A step-by-step guide to strengthening sexual violence services in public health facilities: Lessons and tools from sexual violence services in Africa." Presentations delivered at National Disseminations on the PEPFAR Special Initiative on GBV in Kampala, Uganda and Kigali, Rwanda.

Keesbury, Jill and Mary Zama. January 2011. “Global dissemination of PEPFAR Special Initiative on GBV." Washington, DC. 


\section{KENYA}

\section{Kenyatta National Hospital (KNH) and the Population Council}

Project synopsis: This project involves testing the feasibility of routine screening, referral, and response for intimate partner violence (IPV) in the oldest, largest national public referral hospital in the East African Region (Kenyatta National Hospital).

Policy/program impact at the service delivery level

o Through this project, education and awareness-raising around SGBV occurred broadly throughout $\mathrm{KNH}$ (the largest public referral hospital in the East African region) via multiple provider training sessions in various departments (total \# of providers trained $=121$ ).

o As a result of this study, the Gender-Based Violence Recovery Centre at KNH now screens routinely for IPV, using this study's screening questions.

o The Gender Technical Working Group of the Division of Reproductive Health (Ministry of Health) has recommended that IPV screening be piloted in other hospitals.

o The project has received numerous requests for the IPV screening tool developed under this study, from government bodies and NGOs in the East African region and beyond that would like to pilot a similar effort.

Policy/program impact at the national level

o Findings from the acceptability phase of this study have prompted Kenya's Division of Reproductive Health (within the Ministry of Health) to contact the Population Council to discuss incorporating routine screening for intimate partner violence in the national Standard Operating Procedures for SGBV management, and in the national guidelines for the medical management of survivors of sexual violence.

o The Population Council has played a key role in helping to form a collective of East Africa-based scholars working on intimate partner violence screening to strategically target high-impact regional and international conferences with panel presentations based on evidence emerging from this under-explored area. Scholars within this collective gave a panel presentation on IPV screening at the WHO, Gates Foundation, and Center for AIDS Research-sponsored Integration for Impact international conference in Nairobi in September 2012 (http:/ / integration2012.org/).

\section{Policy/program impact at the international level}

o The World Health Organization (WHO) is currently setting guidelines around routine screening for IPV in developing countries. Evidence from this project is helping to shape the final guidelines.

o The WHO is developing a handbook for IPV screening in developing countries. The draft handbook currently cites the KNH-Population Council IPV screening study.

o Following a presentation of results from this study, Health Ministers from the East, Central and Southern Africa (ECSA) Health Community passed a landmark resolution 
prescribing that routine screening for GBV and child sexual abuse be integrated into sexual and reproductive health and HIV and AIDS services throughout the region.

o From 2013-2015, the UNHCR Africa Regional Support Hub will collaborate with KNH and Population Council to adapt the IPV screening model for refugee settings in Uganda.

o 2 study reports published (one on acceptability, the other on feasibility)

o 1 commentary published in RH Reality Check.

o 10 papers presented at international conferences

\section{Additional funding raised}

o Funding in the amount of USD 250,000 was leveraged from USAID/Kenya to carry out the acceptability phase of this project (2010-2012)

o Funding in the amount of USD 400,000 was obtained from the MacArthur Foundation to replicate IPV screening in refugee settings in Uganda (2013)

\section{Liverpool VCT, Care and Treatment (LVCT)}

Project synopsis: This project involves testing the feasibility of a strategy for improving the collection, documentation and utilization of medico-legal evidence across police stations and health facilities.

\section{Policy/program impact at the service delivery level}

o Through this project, LVCT has developed a model for collaborative health care provider capacity-building involving the Department of Police, the Department of Public Prosecution, and the Government Chemist. This multi-sectoral training approach has since been adopted by Kenya's Sexual Offences Act Task Force.

o Nationally, LVCT is the lead trainer in medical management using this multi-sectoral training approach for community opinion leaders, the police, and health care providers.

o The locally-assembled rape kit developed under this project is the only rape kit available in public health facilities in the country.

o Information, Education, and Communication (IEC) materials developed by LVCT under this project are currently in use within government health facilities - for example:

- A checklist for the documentation of evidence collection

- A brochure and poster entitled "Sexual violence: If it happens"

- A poster on guidelines for documentation of medico-legal examinations

Policy/program impact at the national level

o The national police medical record form and post-rape care (PRC) form (the former is used for entering sexual assault cases into evidence, and the latter is used for recording sexual assault cases within government health facilities) have been revised using evidence from this study. The new PRC form was gazetted in 2012.

o Selected courts in the country now use this revised PRC form as an official evidence document to facilitate sexual violence prosecutions. 
o The Division of Reproductive Health (DRH) within the Ministry of Health has adopted key findings from the two phases of this study:

- The use of the rape kits on a national scale is currently being pursued, with the DRH sourcing for these kits within the Government of Kenya's commodity supply system.

- The national guidelines for the management of sexual violence, and the national training curricula on the clinical management of sexual violence survivors are currently being reviewed with a view to including new evidence from this study.

o Kenya's Sexual Offences Act Task Force is currently developing Standard Operating Procedures. LVCT is participating in this important process, and is in charge of writing a section on evidence collection and management, based on lessons learned from this study.

o Findings from this study informed a review, by LVCT, of medical regulations for implementing Kenya's Sexual Offences Act. The finalized review has since been handed over to Kenya's Attorney General.

Policy/program impact at the international level

- 1 paper based on this work published in the Journal of Forensic Medicine

o 2 study reports published

o 4 papers presented at international conferences

\section{Additional funding raised}

o A three-year 3 year United Nations Trust Fund grant focused on referral mechanisms for evidence across sectors

- A grant from the Elton John AIDS Foundation aimed at establishing a quality assurance framework for post-rape care services 


\section{MALAWI}

Malawi Human Rights Resource Center, Malawi Police Service, Ministry of Health Project synopsis: This project involves determining the feasibility of replicating the Zambian model (developed under this Network) of police provision of emergency contraception to sexual assault survivors in other national contexts - specifically, in Malawi.

Policy/program impact at the service delivery level

o Through this project, log books dedicated to recording information on sexual assault survivors specifically have been introduced within several Victim Support Units in Malawi.

Policy/program impact at the national level

o The Ministry of Health headquarters has given approval for the police to administer EC in Malawi and has asked MHRRC to roll out this program.

o MHRRC has impacted other partners that form part of this project's regular stakeholder meetings. One such partner is UNICEF Malawi (which is setting up one-stop centers (OSC) for SGBV in Malawi), which has incorporated police provision of EC into their OSC model.

o As findings from this project indicated that transporting survivors from the police station to the hospital proved to be a major barrier, UNICEF has now bought a vehicle for transporting anticipated sexual violence survivors that report to the police station first (to facilitate their forthcoming OSC model).

Policy/program impact at the international level

o As part of the South-South technical assistance component of this project, MHRRC received training from South Africa's Medical Research Council (MRC) on the modalities of training health providers and police for this project. The training materials used by MRC have since been adapted for developing the OSC guidelines in Malawi.

o 2 papers presented at an international conference

\section{Additional funding raised}

o MHRRC has secured funds (approximately 1 billion Malawian Kwacha) from the Royal Norwegian Embassy to support mobile Victim Support Units (for reaching communities that do not have easy access to health facilities), and police provision of EC forms an integral part of this new project. 


\section{SOUTH AFRICA}

\section{The Thohoyandou Victim Empowerment Programme (TVEP)}

Project synopsis: This project involves testing the feasibility and effect of a 'Zero Tolerance Village Alliance' (ZTVA) concept, geared toward mobilizing communities to take a stand against violence through educational workshops, dialogues, and campaigns at the community level, and culminating in a traditional pledge-taking ceremony (against GBV) by traditional ruler and other men in the community.

\section{Policy/program impact at the service delivery level}

o Over the life of this project, TVEP has become instrumental in providing guidance to the Departments within the South African government that are positioned to deliver services to TVEP's client base. The Department of Social Development in particular regards TVEP as an integral part of their policy and programming agenda.

o Since the completion of the TVEP intervention, many village elders in South Africa have requested that they and their villages be included in the Zero Tolerance Village Alliance.

o TVEP has rolled out the ZTVA approach in one village, and has trained 5 other community-based organizations (CBOs) to the ZTVA methodology with funding from other sources. TVEP has also received funding directly from the government (in 2013) to train 5 more CBOs to implement the ZTVA model.

Policy/program impact at the national level

o The South African Government (i.e., Department of Social Development) has announced a long-term plan to fund the scale up and roll-out of TVEP's program. Their attention was drawn to TVEP after the publication TVEP's Network-funded e-book (entitled No Excuse for Abuse: A History of the Thohoyandou Victim Empowerment Program) - the only full documentation of the organization's work to date.

\section{Policy/program impact at the international level}

o 1 publication that documents TVEP's history and evolution in program strategy, implementation lessons, and areas for future development. This is the only full documentation of TVEP's work to date and is expected to serve as an important knowledge management, planning, and fundraising tool for the organization.

o 1 study report published in 2012

o 6 papers presented at international conferences

\section{Additional funding raised}

o Recent project results prompted the Joint Gender Fund to provide funding to TVEP to run their intervention in two additional villages.

o TVEP received new funding from the government in 2013 to replicate TVEP's model further, as indicated above.

o With funds obtained by the Population Council in 2013, TVEP will provide technical assistance to UNHCR implementing partners in Uganda to adapt the ZTVA model in refugee settings in Uganda. 


\section{SWAZILAND}

\section{Swaziland Action Group Against Abuse (SWAGAA)}

Project synopsis: This project involves two key activities, 1) leading the development of the first-ever national guidelines for a multi-sectoral response to SGBV in Swaziland, and 2) testing the feasibility and effect of a comprehensive SGBV prevention project for in-school girls in Swaziland.

Policy/program impact at the service delivery level

o A training manual has been developed to guide other schools on the implementation of the GEC-Plus model.

o At a final dissemination meeting, teachers noted the need to continue running the SGBV prevention project (which involves SGBV-focused girls' clubs) in order to reach more children, while community leaders appealed for an expansion of the initiative to reach out-of-school girls in order to empower them to prevent sexual violence, which is highly prevalent in their communities.

o The project's intervention received a pledge of commitment and support from representatives from the Regional Offices of the Ministry of Education.

Policy/program impact at the national level

o The final draft of the National Multi-sectoral Guidelines for the Management of Sexual Violence Cases is completed and awaits final review and approval by the Deputy Prime Minister's Office.

Policy/program impact at the international level

o 1 study report published in 2013

- 4 papers presented at an international conference 


\section{ZAMBIA}

\section{Zambia Police Services (ZPS), Ministry of Health, and the Population Council}

Project synopsis: This project involves 1) the national scale-up and institutionalization of the previously tested model of police provision of emergency contraception (EC) in Zambia, and 2) assessing the feasibility of improving post-exposure prophylaxis (PEP) access for sexual violence survivors through the Zambia Police Services.

\section{Policy/program impact at the service delivery level}

o During Phase I of this project, police were trained to provide EC to survivors of sexual violence that report their cases at police stations. The project contributed to the development of national service delivery protocols for clinical care and police response to sexual assault.

o Under Phase II, the Council is supporting the Zambian government's scale up and institutionalization of police provision of EC.

o Under this project, a multi-sectoral SGBV sub-committee under the Ministry of Health's Safe Motherhood Technical Working group was formed, comprising representatives from the Ministry of Health, ZPS Victim Support Unit, ZPS Medical Unit, Chainama Hospital, and the University Teaching Hospital.

o The success of the police provision of EC project led government officials to request support from the Council in piloting police provision of post-exposure prophylaxis (PEP) for HIV (for sexual assault survivors). This is the focus of the Council's work in this final phase of the project.

\section{Policy/program impact at the national level}

o Through this work, the Council has been able to get both medical and justice sectors in Zambia to acknowledge and accept EC provision at police stations. This tremendous policy accomplishment helped set the stage for the development of the national guidelines (see bullet below) and roll-out.

o The first draft of the National Guidelines for the Multidisciplinary Management of Survivors of GBV in Zambia was actually a document developed by the Population Council under Phase I of this project in 2007. The Zambian government realized the importance of this endeavor and asked that the Council assist with developing the document into national guidance. In May 2012, the guidelines were officially adopted by the government. Importantly, these national guidelines actively embrace the comprehensive model of care that has been continuously promoted under this SIDA project, and they allow for police provision of EC, an innovative model that the Council introduced, piloted, and is now scaling up.

o Results from the police provision of EC project led Zambian officials to request that the Council scale up and institutionalize this project nationally, and this scale-up process has occurred since then.

\section{Policy/program impact at the international level}

o The police provision of EC model has been shared globally, and was successfully replicated in Malawi under this Network.

o 1 study report published

o 4 papers presented at international conferences 